\title{
Resuscitation experience in the Falkland Islands campaign
}

\author{
J G WILLIAMS, T R D RILEY, R A MOODY
}

The recent campaign to retake the Falkland Islands was a novel military exercise from many points of view. This was particularly so for the medical support, which required much improvisation at all levels. Several surgical teams from the Royal Navy and the Royal Army Medical Corps were deployed in support of both the fleet and the troops on land. Two Royal Naval teams embarked in SS Canberra, and the journey south on board provided an opportunity to discuss and decide on a specific resuscitation policy for the casualties that might be encountered. We discuss the details of this policy and the results of using it.

\section{Resuscitation policy}

The essence of the resuscitation policy was that it should be simple and straightforward, using a minimum of procedures, drugs, and fluids. This would aid the speed at which large numbers of casualties could be resuscitated. Once formulated, it was taught to all personnel likely to be concerned in resuscitation.

Airway-The airway was to be managed in the usual manner with clearance of all foreign material from the mouth and pharynx, support for the jaw, and insertion of a Guedel airway if necessary. Facilities for endotracheal intubation and assisted ventilation would be available in the resuscitation area. Patients with maxillofacial injuries would be nursed prone, but patients with other injuries would probably be supine when attended. Any penetrating injury of the chest or any clinical evidence of pneumothorax would require the insertion of an intercostal chest drain in the mid-axillary line between the fourth and fifth or fifth and six ribs and directed apically on the side of the injury. These patients would be nursed sitting up, if not contraindicated by shock.

Analgesia-Intravenous morphine was to be used, diluted $15 \mathrm{mg}$

RN Hospital, Plymouth, Devon PL1 3JY

J G WILLIAMS, MSC, MRCP, surgeon commander, Royal Navy

T R D RILEY, MB, BS, surgeon lieutenant commander, Royal Navy

R A MOODY, MB, FFARCS, surgeon lieutenant commander, Royal Navy in $5 \mathrm{ml}$ of water, and given in small doses $(3 \mathrm{mg}$ ) often, titrated according to pain. The importance of checking the dose and time of any analgesia given previously was emphasised. For chest injuries it was planned to give buprenorphine hydrochloride $0.3-0.6 \mathrm{mg}$ or, if unavailable, pentazocine $30-60 \mathrm{mg}$ intravenously. Inhalational Entonox $(50 \%$ nitrous oxide $/ 50 \%$ oxygen) would also be available.

Antibiotics-All patients with open wounds were to be given benzylpenicillin intravenously, one megaunit immediately and repeated every six hours for 24 hours. Patients with penetrating head wounds were to be given sulphadimidine $1 \mathrm{~g}$ four times a day intramuscularly in addition. Those with abdominal wounds were to be given immediately gentamicin $80 \mathrm{mg}$ intravenously and metronidazole $500 \mathrm{mg}$ intravenously. With these more complicated injuries postoperative antibiotic treatment was to be defined by the operating surgeon. It was decided not to attempt to exclude penicillin hypersensitivity in view of the difficulties in obtaining an accurate history.

Antitetanus-It was decided not to attempt to administer tetanus toxoid vaccine to all troops before the expected battles as their basic level of immunity would have been high due to normal service vaccination programmes, and the wide distribution of troops among the ships of the Task Force would have made it impossible to cover all the combatants with this policy. Thus postinjury boosters would still need to be given and in some cases would have resulted in three antitetanus injections over only a few months. If was therefore decided to limit active antitetanus immunisation to booster injections given during the resuscitation of all casualties with penetrating injuries or burns. Human antitetanus immunoglobulin was available for use at the discretion of the surgeon.

Other drugs-Diazepam $10 \mathrm{mg}$ in $2 \mathrm{ml}$ was to be given for excess anxiety persisting when pain had been controlled by morphine. Naloxone $0.4 \mathrm{mg}$ diluted to $2 \mathrm{ml}$ was available to reverse opiate overdosage. Methylprednisolone $1 \mathrm{~g}$ immediately followed by $0.5 \mathrm{~g}$ every six hours was to be given for any lung injury whether caused by trauma, blast, smoke inhalation, or drowning. It was not planned to give steroids routinely for shocked patients except for irreversible shock. Adrenaline $1 \mathrm{mg}$ in $500 \mathrm{ml} \mathrm{5 \%}$ dextrose was to be set up in the resuscitation area daily for the treatment of anaphylactic shock.

Oxygen was to be given to all shocked patients through a moderate concentration Venturi mask.

Fluid replacement-Intravenous infusions were to start after a blood sample had been taken for cross match through a large bore intravenous cannula sited in a forearm vein as soon as possible after 
admission. If vasoconstriction precluded peripheral venepuncture a cut down or central line was to be inserted. Initial infusion would be with one litre of compound sodium lactate solution followed by $500 \mathrm{ml}$ of polygeline. Polygeline was chosen in preference to other colloids because of its unbreakable bottle, light weight, temperature stability, and because it would not interfere with blood cross match. The speed of infusion was to depend on clinical judgment. The sequence of compound sodium lactate followed by polygeline would be repeated if clinically indicated. Cross matched blood would be given, if indicated, when available. Cross match times would be half an hour for an urgent cross match and two hours for a routine cross match, though a small stock of $\mathrm{O}$-negative blood was to be held in the resuscitation area for lifesaving urgent transfusion.

Burns-Burns cases were to be treated with attention to the airway, analgesia, penicillin, and tetanus toxoid as already described. Intravenous fluids would be given at $120 \mathrm{ml}$ per $1 \%$ of burn over the 24 hours after the time of the burn, using crystalloid (compound sodium lactate) and colloid (polygeline) in equal proportions plus additional crystalloid for normal daily requirements. It was not planned to give intravenous treatment unless the burnt area was $15^{\prime \prime}$ of the total body surface area, or greater. Silver sulphadiazine cream was to be used topically with polyethylene bag occlusion for hands and feet. Any evidence of blast or smoke inhalation injury to the lung would be an indication for methylprednisolone $1 \mathrm{~g}$ immediately followed by $0.5 \mathrm{~g}$ every six hours.

Monitoring-The usual measurements of pulse, blood pressure, respiratory rate, and level of consciousness would be used. It was not planned to use central venous lines for measuring venous pressure.

\section{Clinicai results}

The main reception areas for treating casualties from the time of the landings on 21 May to the surrender were first SS Canberra (fig 1)

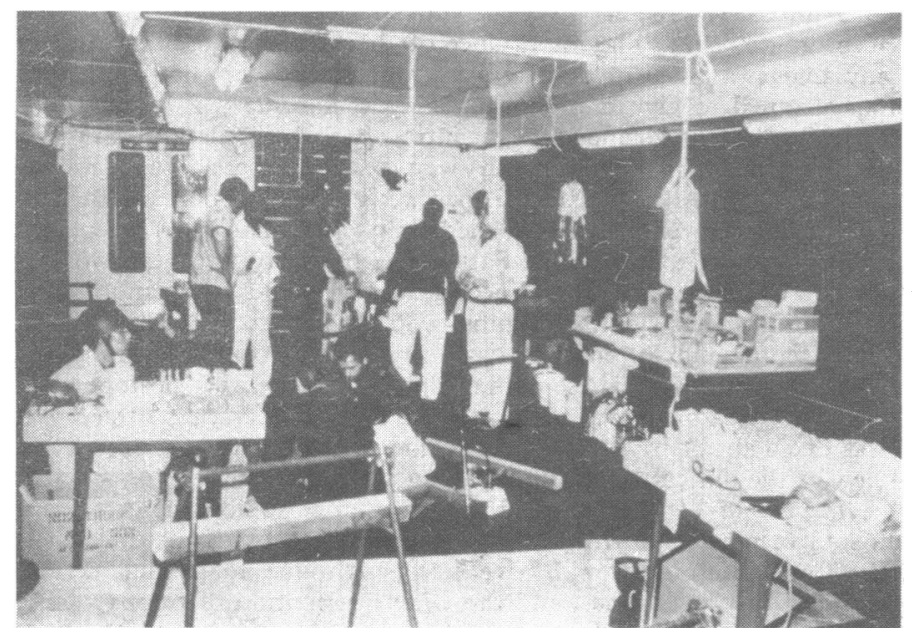

FIG 1 -Resuscitation area $S S$ Canberra. Doctors are in white boiler suits.

and then a disused refrigeration plant at Ajax Bay (fig 2), which was later supplemented by forward surgical stations at Teal Inlet (fig 3) and Fitzroy. We were present and responsible for the resuscitation at all of these sites except Fitzroy, and the policy as described was used in these areas where over 500 battle casualties were treated. Overall, the simplicity of the policy and the planning and rehearsal that went into it paid dividends. Resuscitation proved to be rapid, efficient, and effective. Only three patients died at this stage of their management. One reached Ajax Bay irreversibly shocked, having lost both legs when an ammunition dump exploded at Goose Green, and could not be resuscitated, and two were admitted to Teal Inlet moribund from severe penetrating high velocity gunshot wounds to the head.

Specific aspects of resuscitation deserve the following comments

Airway-No upper airway problems were encountered, and no patients required endotracheal intubation before surgery. This included several admissions with wounds to the head, face, or neck who were nursed prone to maintain their airway, but even these patients appeared to have travelled well in a variety of positions

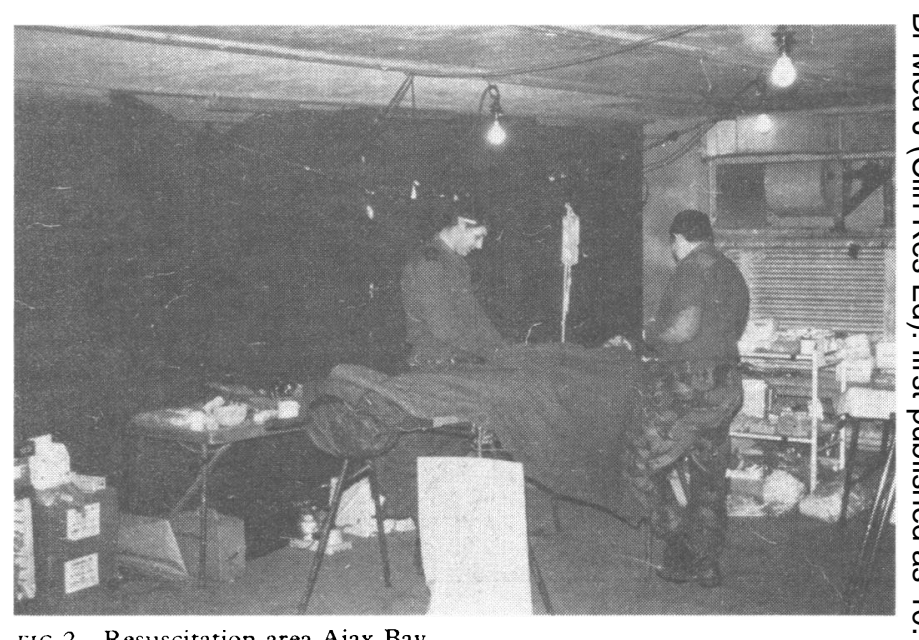

FIG 2-Resuscitation area Ajax Bay.

without problems. All penetrating wounds of the chest were treated with intercostal drainage with, in many cases, relief of respiratory iv embarrassment by the drainage of substantial volumes of blood. o Heimlich valves were used to provide a one way seal to these drains of and these often became blocked if blood was draining. The only solution was to change the valves frequently but a non-blocking seal . would have been an advantage. Several patients who had been exposed to blast had pneumothoraces without external evidence of injury and $\mathrm{v}$ these also received intercostal drains. Sucking chest wounds were occluded with airtight dressings. With these measures, nursing in the $\mathrm{G}$ sitting position, and giving oxygen to those who were clinically cyanosed or in whom restlessness suggested hypoxia, all chest wounds were managed in slow time, and no patient required immediate emergency surgery.

Analgesia-Morphine given in small doses intravenously at frequent intervals was very effective in controlling pain and relieving anxiety. No problems were encountered with respiratory depression and in the event non-opiates were not used as an alternative to morphine for chest injuries.

Antibiotics-No specific figures can be given, but infection did not prove to be a problem provided that the surgical pinciples of extensive $\frac{\mathrm{\Phi}}{\mathrm{Q}}$ wound debridement and delayed primary suture were followed. Antibiotic policy as planned was followed with the exception of penetrating $\overrightarrow{\overrightarrow{0}}$ head wounds when metronidazole was given in addition to penicillin 3 and sulphadimidine when it was learnt that some patients with head injuries evacuated to the hospital ship $S S U$ ganda had improved when metronidazole was added to their treatment. No cases of tetanus, gas gangrene, or hypersensitivity to penicillin were seen.

Other drugs-Diazepam was used in small doses in a few patients who remained agitated, noisy, and disruptive to other patients despite adequate pain relief with morphine. These were all patients who had suffered painful superficial facial and hand burns. Diazepam $5 \mathrm{mg} \delta$

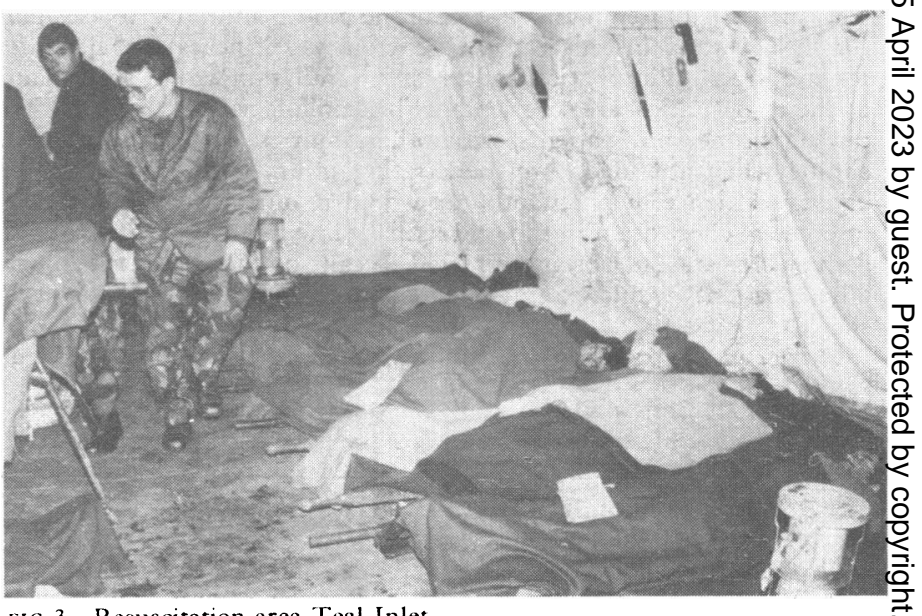

FIG 3-Resuscitation area Teal Inlet 
was most effective in controlling this agitated behaviour without harmful synergism with morphine. No patients required inotropic cardiac support in the resuscitation areas.

Steroids-Methylprednisolone was given to all cases of near drowning, blast lung, or smoke inhalation. Treatment was started as soon as possible and continued for 24 hours. Three cases of severe blast lung were seen: in all three clinical evidence for pulmonary oedema was apparent at admission and before treatment with methylprednisolone had been started. Nevertheless, all were managed with high doses of methylprednisolone $(1 \mathrm{~g}$ immediately followed by $1 \mathrm{~g}$ every six hours for 24 hours) plus frusemide as necessary and oxygen. Despite severe pulmonary oedema and profound hypoxia these patients all survived. One required intubation and mechanical ventilation, though this could not be started until 24 hours after injury when he was transferred to $S S U$ ganda. Methylprednisolone $(1 \mathrm{~g}$ immediately, $0.5 \mathrm{~g}$ every six hours for 24 hours) was given to 57 patients with burns from the Sir Galahad who were treated at Ajax Bay. None of these patients developed respiratory complications despite exposure to blast and smoke. Methylprednisolone was not given to patients with gunshot wounds to the chest, and no problems were encountered.

Intravenous cannulation-In most patients it was possible to site a large bore cannula into a forearm vein on arrival. Central lines through the internal jugular or subclavian approach were used in several patients who were severely shocked on arrival but these seemed to confer no specific advantage over finding and cannulating a forearm vein. Several patients had received initial fluid replacement in the field from a forward regimental aid post, but cold and movement in transit almost invariably meant that these venous lines had ceased to function by the time the patients reached the surgical stations.

Fluid replacement-Many patients were severely peripherally vasoconstricted when admitted to the surgical stations but this was related to cold as much as to blood loss. In a fit young population circulatory resuscitation proved very effective, with only one patient, already described, in irreversible shock. Most patients with simple gunshot wounds required only a litre of compound sodium lactate followed by $500 \mathrm{ml}$ of polygeline before surgery. In those in whom blood loss had been serious blood was given as soon as available. On board the Canberra cross matched blood was used but ashore cross match was impractical for lack of both time and facilities and group compatible blood was given. No transfusion reactions were seen in either location.

Burns-After the bombing of the Sir Galahad 130 patients were admitted to Ajax Bay in one hour. Seventy three of these casualties were suffering from relatively minor trauma or burns and were transferred immediately to ships in San Carlos Water. Most of the remaining 57 were suffering from burns to the face and hands. Sheer weight of numbers meant that a standard intravenous replacement regimen had to be adopted, and all patients with greater than $10 \%$ burns received intravenous fluids-about three litres compound sodium lactate and one and a half litres polygeline-over the next 20 hours, before transfer to the Uganda. This resuscitation proved necessary but satisfactory for all except a few patients with more extensive burns $(20-30 \%)$ who were underinfused as judged by haematocrit estimation performed the next day. Pain relief was good with morphine, though several agitated patients required a small dose of diazepam ( $5 \mathrm{mg}$ ) in addition. Burns were treated with silver sulphadiazine cream and exposure, except for the hands which were enclosed in polyethylene bags.

\section{Discussion}

The resuscitation policy as described was simple and conventional, ${ }^{1}$ and no new lessons were learnt when using it in the resuscitation of over 500 patients. Although the injuries were often severe and multiple, the injured on the British side were highly trained, fit men with a strong will to survive. About $20 \%$ of the casualties treated were Argentines and the fitness of these cannot be gauged nor their will to survive, though many of them were clearly profoundly relieved to be out of the battle and out of the cold. Language difficulties and fear made pain relief and sedation more difficult to achieve but there were no other specific problems.

The high success rate achieved in the resuscitation of a large number of casualties, some with severe injuries and many who had remained in the field for some hours before evacuation, is a testament to this fitness and morale, and also to the skill and training of the personnel concerned. The results may also reflect some degree of selection in that those patients with the most severe injuries or obstructed airways may have died before evacuation. Intensive rehearsal before the invasion enabled paramedical personnel to help with resuscitation so that no delays occurred once patients were admitted, even at times of mass casualty reception. The 57 patients admitted after the bombing of the Sir Galahad were all received at Ajax Bay within one hour, but none had to wait a considerable or dangerous length of time for treatment. The standardisation of resuscitation procedure and the elimination of choice in the use of fluids and drugs contributed greatly to the speed of this treatment.

The availability of blood also contributed greatly to the effective resuscitation of the more severely wounded. Ashore, blood was given without cross match but with confirmation of the patient's group by serology, and the time gained outweighed the dangers of possible mismatch. In the event no transfusion reactions were seen, though the possibility of sensitisation to future transfusion remains.

The only other fluids used for intravenous infusion for resuscitation were compound sodium lactate and polygeline. Other crystalloid solutions such as saline, dextrosesaline, or dextrose, and colloid such as dextran or plasma were not used and not missed. Similarly, only penicillin was used to treat wounds, apart from the special conditions described, and this was effective and safe. The possibility of anaphylactic reactions was considered, but it was thought impractical and too time consuming to try to elicit a history of this, particularly when such a history would probably be unreliable. Adrenaline was available for the treatment of any anaphylactic reaction but there was none, justifying the selection of this policy.

We acknowledge with thanks the many medical staff, RN, RAMC, and $\mathrm{P}$ and $\mathrm{O}$, in SS Canberra and ashore who contributed to the formulation and to the execution of this resuscitation policy. We also thank Mrs Janice Saul for typing the manuscript. We are grateful to the Medical Director General (Navy) for permission to publish this article.

\section{Reference}

${ }^{1}$ Kirby NG, Blackburn G. Field surgery pocket book. London: HMSO, 1981.

(Accepted 18 fanuary 1983)

\section{Clinical curio: supermarket elbow}

During many years of orthopaedic and traumatic surgery $I$ have been impressed by the many patients, mainly housewives, who have attended outpatient clinics complaining of painful elbows. Many cases are diagnosed as "tennis elbow" and are treated as such, ${ }^{1}$ while those that are bilateral often need attention to the neck and shoulder girdle musculature. The painful elbow in those who do a lot of shopping in small or large supermarkets is due in my opinion to the handles of the basket being placed the wrong way round: they force the carrier to use a supinated grip with a flexed elbow instead of a semipronated grip as in lifting a briefcase or a suitcase. Women have a natural carrying angle at the elbow, which may compensate to some degree, but carrying a heavy basket with the handles placed as they are at present puts an undue strain on the flexed elbow; the whole arm from shoulder down should be taking the brunt of the load. The position of the supermarket basket handles appears to be the same all over the world, but a single handle fixed on a swivel at the long ends of the basket would be simpler. I am sure this arrangement would add to the comfort of the heavily laden supermarket customer and would reduce elbow strain.L C L GONET, consultant orthopaedic surgeon, London W1 1AA. 'Gonet LCL. "Tennis elbow"-A new conception. Annals of Physical Medicine
1957;4:70-3. 